\title{
NADH dehydrogenase deficiency results in low respiration rate and improved aerobic growth of Zymomonas mobilis
}

Correspondence

Uldis Kalnenieks

kalnen@lanet.lv

Received 24 August 2007

Revised 13 November 2007

Accepted 27 November 2007

\author{
Uldis Kalnenieks, ${ }^{1}$ Nina Galinina, ${ }^{1}$ Inese Strazdina, ${ }^{1}$ Zane Kravale, ${ }^{1}$ \\ James L. Pickford, ${ }^{2}$ Reinis Rutkis ${ }^{1}$ and Robert K. Poole ${ }^{2}$
${ }^{1}$ Institute of Microbiology and Biotechnology, University of Latvia, Kronvalda Boulv. 4, LV-1586, Riga, Latvia
${ }^{2}$ Department of Molecular Biology and Biotechnology, The University of Sheffield, Firth Court, Western Bank, Sheffield S10 2TN, UK

The respiratory chain of the ethanol-producing bacterium Zymomonas mobilis is able to oxidize both species of nicotinamide cofactors, NADH and NADPH. A mutant strain with a chloramphenicol-resistance determinant inserted in ndh (encoding an NADH: CoO oxidoreductase of type II) lacked the membrane NADH and NADPH oxidase activities, while its respiratory $D$-lactate oxidase activity was increased. Cells of the mutant strain showed a very low respiration rate with glucose and no respiration with ethanol. The aerobic growth rate of the mutant was elevated; exponential growth persisted longer, resulting in higher biomass densities. For the parent strain a similar effect of aerobic growth stimulation was achieved previously in the presence of submillimolar cyanide concentrations. It is concluded (i) that the respiratory chain of $Z$. mobilis contains only one functional $\mathrm{NAD}(\mathrm{P}) \mathrm{H}$ dehydrogenase, product of the $n d h$ gene, and (ii) that inhibition of respiration, whether resulting from a mutation or from inhibitor action, stimulates $Z$. mobilis aerobic growth due to redirection of the NADH flux from respiration to ethanol synthesis, thus minimizing accumulation of toxic intermediates by contributing to the reduction of acetaldehyde to ethanol.

\section{INTRODUCTION}

Zymomonas mobilis is a Gram-negative facultatively anaerobic bacterium with an efficient and very rapidly operating homoethanol fermentation pathway (Rogers et al., 1982). Recombinant $Z$. mobilis capable of simultaneous fermentation of pentose and hexose sugars is regarded as having great promise for fuel ethanol production from wood hydrolysates (Dien et al., 2003). Not surprisingly, the fermentative catabolism of this bacterium has been studied in great detail due to its potential biotechnological significance (Viikari \& Berry, 1988; Conway, 1992; Sprenger, 1996). However, major uncertainties still persist in our understanding of the structure and function of its electron-transport chain (Kalnenieks, 2006). Inhibitor analysis points to a branched structure of the electron-transport pathway, with several alternative dehydrogenases and terminal oxidases (Strohdeicher et al., 1990; Kalnenieks et al., 1996, 1998). Accordingly, the genome sequence of $Z$. mobilis (Seo et al., 2005) reveals genes encoding several $\mathrm{NAD}(\mathrm{P}) \mathrm{H}$ dehydrogenases, as well as electron-transport dehydrogenases for Dlactate and glucose, several $c$-type cytochromes, the $b d$ terminal oxidase and the $b c_{1}$ complex (CoQ: cytochrome $c$ oxidoreductase). Most probably, some of the genes that encode key components of the respiratory chain still await identification, in particular those of the oxidase(s) terminating the putative $b c_{1}$ electron-transport branch. Serious ambiguities can be noted when the genomic information is compared to the existing biochemical data on the respiratory dehydrogenases for NADH and NADPH (Strohdeicher et al., 1990; Kalnenieks et al., 1996, 1998; Seo et al., 2005). Thus, although the site I energy-coupling (Kalnenieks et al., 1995) and kinetic parameters for NADH oxidation in membranes (Kalnenieks et al., 1996) suggest presence of the NADH dehydrogenase complex I, nevertheless the six genes of the $Z$. mobilis genome encoding the putative NADH: ubiquinone oxidoreductase complex do not bear homology to those of the nuo operon of Escherichia coli. They appear to be closely homologous to the genes of the $r n f$ operon, encoding a recently discovered membrane electron-transport complex, which is involved in electron transport to nitrogenase in the photosynthetic bacterium Rhodobacter capsulatus (Schmehl et al., 1993). Genes for the type II NADH dehydrogenase ( $n d h)$, and for several other $\mathrm{NAD}(\mathrm{P}) \mathrm{H}$ dehydrogenases, have also been annotated in the genome, but the corresponding activities in the respiratory chain have so far not been identified. 
Electron transport in Z. mobilis provokes special interest because of its unusual physiological manifestations. Although the cytoplasmic membrane of $Z$. mobilis carries a functional $\mathrm{H}^{+}$-ATP synthase complex (Reyes \& Scopes, 1991), this bacterium does not use its respiratory chain to supply energy for aerobic growth in the same way as the majority of aerobic and facultatively anaerobic microorganisms do. Indeed, its respiratory metabolism seems to be inhibitory for this bacterium, largely because of the accumulation of acetaldehyde and other toxic byproducts (Viikari, 1986; Viikari \& Berry, 1988). A pronounced stimulation of aerobic growth takes place when respiration is partially inhibited by addition of cyanide at submillimolar concentrations (Kalnenieks et al., 2000). Oxygen uptake in aerobic cultures of $Z$. mobilis proceeds at a relatively high rate, while the biomass yields under oxic conditions are low, typically well below $10 \mathrm{~g}$ dry weight per mole of glucose (Belaïch \& Senez, 1965; Bringer et al., 1984; Pankova et al., 1985). It is not clear whether the respiratory chain per se plays any role in the energetics of growth or stationary-phase survival, and whether there might be some alternative physiological functions of electron transport (Kalnenieks, 2006). Obviously, without a clear picture of the electron-transport pathways, it will not be possible to explain the function of the respiratory chain in $Z$. mobilis.

Respiratory knockout mutants have contributed greatly to research on bacterial electron transport during the last two decades (Calhoun et al., 1993; Poole \& Cook, 2000), helping to reveal the structure and energy-coupling efficiency of particular electron-transport branches. To our knowledge, no respiratory mutants have so far been reported for $Z$. mobilis. This largely explains the gaps in our understanding of the electron transport in this bacterium. Here we report the construction and study of a Z. mobilis mutant that is deficient in the NADH : CoQ oxidoreductase of type II (Ndh). The mutant shows profound alterations of the respiratory phenotype, namely a dramatic decrease of the respiration rate and yet an improvement of the aerobic growth capacity.

\section{METHODS}

Bacterial strains, plasmids and transformation. E. coli JM109 and plasmid pGEM-3Zf $(+)$ were purchased from Promega. Strain JM109 was used as the host for cloning of the recombinant plasmids. $Z$. mobilis ATCC 29191 (Zm6) was maintained and cultivated as described previously (Kalnenieks et al., 1993, 2003). Plasmids constructed and used in the present work are listed in Table 1. E. coli was transformed by the $\mathrm{CaCl}_{2}$ procedure as described by Sambrook et al. (1989). Z. mobilis was transformed by electroporation (Liang \& Lee, 1998).

PCR and DNA manipulations. Genomic DNA from Z. mobilis was isolated using a Promega Wizard Genomic DNA purification kit, following the manufacturer's instructions. The QIAprep Spin Miniprep kit (Qiagen) was used for plasmid isolation. The Z. mobilis $n d h$ gene (Z. mobilis ZM4 genome sequence; GenBank accession AE008692) was amplified by PCR, using primers Z.m.ndh1 (AGAGAATAGAGGGGATCCATGTCGAAGAAT) and Z.m.ndh2 (ATCAGTATAATTAAGCTTTAGGGCGTAACA) supplied by Sigma Genosys. The engineered restriction sites for BamHI and HindIII, respectively, are underlined. PCRs were carried out in a ThermoHybaid gradient thermocycler, using Accuzyme DNA polymerase (Bioline). Purification of the amplified DNA fragment was done with the QIAquick PCR purification kit (Qiagen). The QIAquick gel extraction kit (Qiagen) was used for the recovery of plasmids and PCR products from agarose gels. T4 DNA ligase (Fermentas) was used in ligation assays. Restriction, ligation and cloning was done essentially by standard procedures (Sambrook et al., 1989). All DNA constructs were confirmed by DNA sequencing, done by Lark Technologies.

Cultivation and preparation of membranes. Batch cultivations were carried out at $30{ }^{\circ} \mathrm{C}$, either in $300 \mathrm{ml}$ shaken flasks, $120 \mathrm{ml}$ culture volume, on a shaker at 120 r.p.m., or in a Labfors fermenter (Infors) of 11 working volume with air flow $2.51 \mathrm{~min}^{-1}$ and stirring rate 500 r.p.m. For some cultivations, gassing with nitrogen or air was performed, as stated in Results. The growth medium contained glucose $\left(50 \mathrm{~g} \mathrm{l}^{-1}\right)$, yeast extract $\left(5 \mathrm{~g} \mathrm{l}^{-1}\right)$, potassium dihydrogen phosphate $\left(1 \mathrm{~g} \mathrm{l}^{-1}\right)$, ammonium sulfate $\left(1 \mathrm{~g} \mathrm{l}^{-1}\right)$ and magnesium sulfate $\left(0.5 \mathrm{~g} \mathrm{l}^{-1}\right), \mathrm{pH}$ 5.5. To compare various modes of aeration, the oxygen volumetric mass transfer coefficient $\left(K_{\mathrm{L}} a, \mathrm{~s}^{-1}\right)$ was determined by the gassing-out method, as described by Demirtas et al. (2003). For preparation of cytoplasmic membrane vesicles, cells were sedimented by centrifugation at 5000 r.p.m. for $15 \mathrm{~min}$, resuspended in $100 \mathrm{mM}$ potassium phosphate buffer, containing $2 \mathrm{mM}$ magnesium sulfate, $\mathrm{pH} 6.9$, and disrupted by disintegration with abrasive quartz beads, $125-150 \mu \mathrm{m}$ diameter, in a homogenizer at 1000 r.p.m. for $3.5 \mathrm{~min}$. Separation of cytoplasmic membranes was performed as described previously (Kalnenieks et al., 1993).

Analytical methods. Concentration of dissolved oxygen was monitored by Clark-type oxygen electrodes. An autoclavable Ingold electrode was used in the fermenter, and a Radiometer electrode with a thermostatted electrode cell for oxygen uptake measurements in washed cell or membrane vesicle suspensions. Ethanol concentration

Table 1. Plasmids used in the study

\begin{tabular}{|c|c|c|}
\hline Plasmid & Characteristics & Source \\
\hline pGEM-3Zf $(+)$ & $A m p^{r}$ & Promega \\
\hline $\mathrm{pBT}$ & $\mathrm{Cm}^{\mathrm{r}}$ & Stratagene \\
\hline pGEMndh & $\begin{array}{l}\text { pGEM-Zf }(+) \text { derivative, carrying a } 1.3 \mathrm{~kb} \text { fragment of PCR-amplified genomic DNA with } \\
\text { the ORF of the } n d h \text { gene cloned between the HindIII and BamHI sites of the multiple } \\
\text { cloning site }\end{array}$ & Present work \\
\hline pGEMndh :: $\mathrm{cm}^{\mathrm{r}}$ & $\begin{array}{l}\text { pGEMndh derivative, carrying a } 1.3 \mathrm{~kb} \text { fragment of pBT with } 0.7 \mathrm{~kb} \text { of the chloramphenicol } \\
\text { resistance ORF inserted in the AgeI site of } n d h\end{array}$ & Present work \\
\hline
\end{tabular}


was determined by gas chromatography (Varian). Acetaldehyde was assayed via the alcohol dehydrogenase reaction, and glucose was assayed by the glucose oxidase method, as described previously (Kalnenieks et al., 2000). Protein concentration in membrane samples was determined according to Markwell et al. (1978). Cell concentration was determined as $\mathrm{OD}_{550}$, and dry cell mass of the suspensions was calculated by reference to a calibration curve. All results are means of at least three replicates.

\section{RESULTS AND DISCUSSION}

\section{Construction of the $\boldsymbol{n d h}$-deficient strain}

Amplification and cloning of $n d h$, using pGEM-3Zf $(+)$ plasmid vector, and the strategy for construction of the $n d h$-deficient $Z$. mobilis strain was essentially the same as used previously for construction of a strain deficient in alcohol dehydrogenase (ADH II) activity (Kalnenieks et al., 2006). The amplified $1.33 \mathrm{~kb}$ DNA fragment, starting $18 \mathrm{bp}$ upstream and ending $162 \mathrm{bp}$ downstream of the ORF of Z. mobilis $n d h$, was double-digested with BamHI and HindIII, and was directionally cloned between the BamHI and HindIII restriction sites of the multiple cloning site of plasmid pGEM-3Zf $(+$ ), yielding plasmid pGEMndh (Table 1). Plasmid pBT was digested with AgeI (BshTI) to obtain three fragments, of approximately 1.6, 1.3 and $0.3 \mathrm{~kb}$. The $1.3 \mathrm{~kb}$ AgeI digestion fragment carried the chloramphenicol-resistance determinant (659 bp ORF of the chloramphenicol acetyltransferase gene). AgeI digestion was chosen because plasmid pGEMndh contained only one AgeI restriction site that was localized in the $n d h$ insert. After digestion of pGEMndh with Agel, the $1.3 \mathrm{~kb}$ fragment of pBT was cloned in the middle of $n d h$ to yield plasmid pGEMndh:: $\mathrm{cm}^{\mathrm{r}}$. Plasmid pGEMndh $:: \mathrm{cm}^{\mathrm{r}}$ was used to transform $Z$. mobilis by electroporation, and selection for homologous recombinants was carried out on plates containing chloramphenicol $\left(30 \mu \mathrm{g} \mathrm{ml}^{-1}\right)$. Several colonies were screened for the $n d h:: \mathrm{cm}^{r}$ genotype by PCR on the genomic DNA template with primers Z.m.ndh1 and Z.m.ndh2.

\section{Effect of $n d h$ disruption on the respiratory oxidase activities}

Data on the respiratory oxidase activities in membrane preparations obtained from cultures of strains $\mathrm{Zm} 6$ and the mutant $n d h:: \mathrm{cm}^{r}$ grown under various conditions of aeration are presented in Fig. 1. In agreement with previous data (Bringer et al., 1984; Kim et al., 1995), NADH oxidase was the major respiratory activity in $\mathrm{Zm} 6$ membranes. In cultures grown either without aeration (in shaken flasks under nitrogen gas) (Fig. 1a), or under moderate aeration $\left(K_{\mathrm{L}} a 0.27 \mathrm{~s}^{-1}\right)$ on the shaker at 120 r.p.m. (Fig. 1b), its activity was close to $0.3 \mathrm{U}$ (mg membrane protein $)^{-1}$. NADPH oxidase activity constituted approximately 25$50 \%$ of this value. Both oxidase activities were approximately doubled when Zm6 was grown with hyperventilation (Fig. 1c) in shaken flasks at 120 r.p.m., additionally gassed with air $\left(11 \mathrm{~min}^{-1}, K_{\mathrm{L}} a 1.18 \mathrm{~s}^{-1}\right)$. Minor D-lactate oxidase (Kalnenieks et al., 1998) and glucose oxidase activities (Strohdeicher et al., 1990) were also detectable; both of them were likewise induced by aeration (Fig. 1b, c).

Remarkably, disruption of $n d h$ by insertion of the chloramphenicol-resistance determinant resulted in a total loss of NADH and NADPH oxidase activities in the mutant cell membranes under all tested culture aeration regimes. However, membranes from mutant cells grown under aerated conditions overexpressed the membrane D-lactate oxidase (Fig. 1b, c). D-Lactate oxidase activity in aerobically grown $n d h:: \mathrm{cm}^{r}$ appeared to be the dominant oxidase activity, and was higher than in Zm6 under all aeration conditions. It is tempting to think that the elevated Dlactate oxidase in aerated cells has some physiological importance for the aerobic metabolism of $Z$. mobilis $n d h:: \mathrm{cm}^{r}$. In the mutant strain D-lactate dehydrogenase might serve to compensate for the lack of respiratory $\mathrm{NAD}(\mathrm{P}) \mathrm{H}$ oxidation. A somewhat similar effect was reported for a Corynebacterium glutamicum type II NADH dehydrogenase-deficient strain, in which elevated levels of membrane L-lactate oxidase were found (Nantapong et al., 2004). In principle, D-lactate in $Z$.
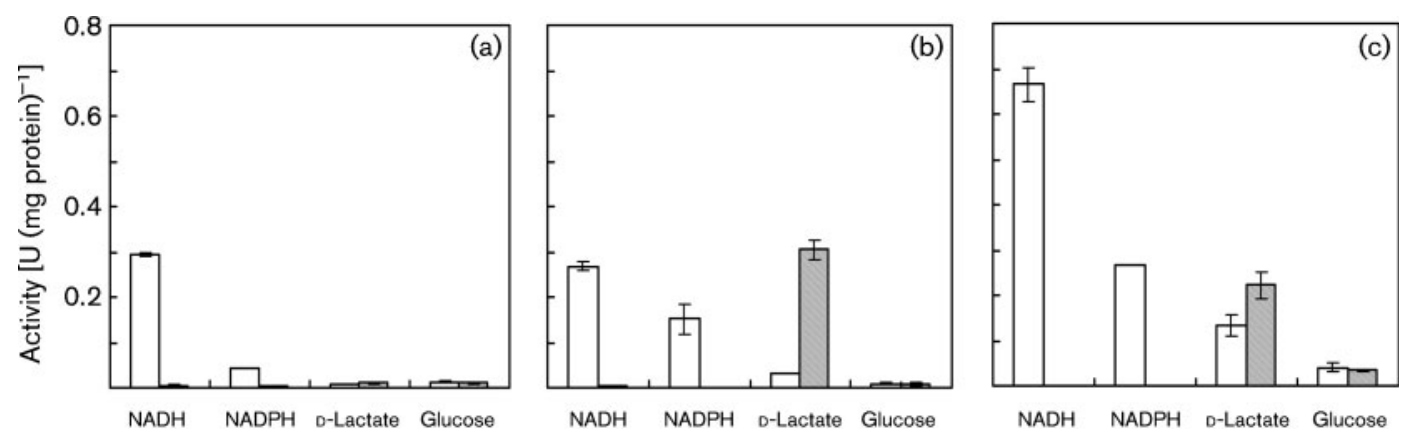

Fig. 1. Activity of the respiratory oxidases in membrane preparations, obtained from cells of Zm6 (white bars) and $n d h:: \mathrm{cm}^{r}$ (shaded bars) cultivated anaerobically (a), aerobically on a shaker (b), and aerobically with additional gassing with air (c) (see text for details). Data are means $\pm \mathrm{SEM}$. 


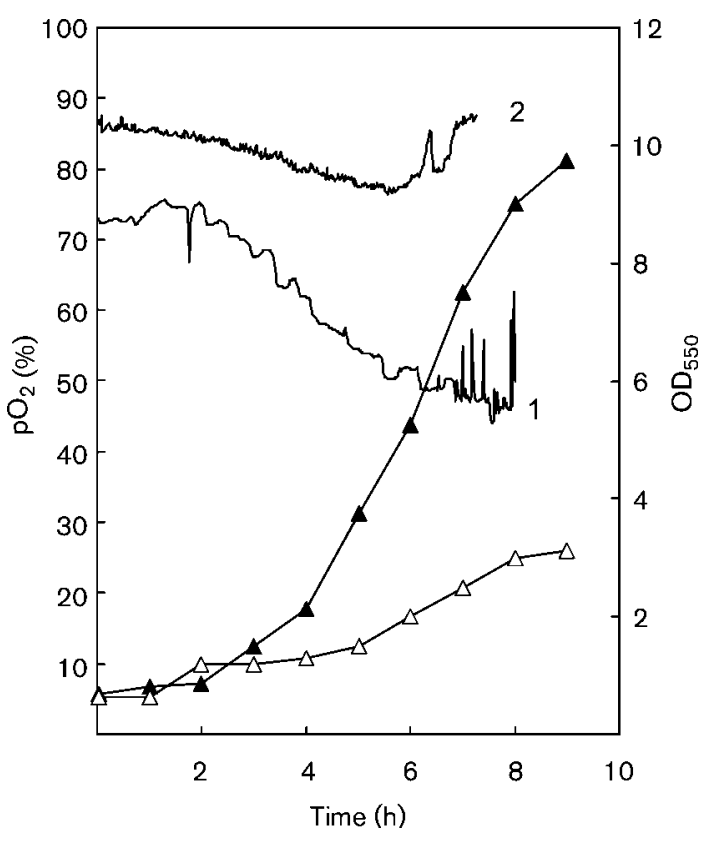

Fig. 2. Aerobic batch cultivation of $\mathrm{Zm6}(\triangle)$ and $n d h:: \mathrm{cm}^{r}(\mathbf{\Delta})$ in a fermenter with continuous monitoring of $\mathrm{pO}_{2}(1, \mathrm{Zm} 6 ; 2$, $\left.n d h:: \mathrm{cm}^{\prime}\right)$.

mobilis might be produced from pyruvate and NADH by the cytoplasmic lactate dehydrogenase, and then reoxidized by the respiratory D-lactate dehydrogenase, forming a kind of 'lactate shunt' for NADH reoxidation. However, the rate of oxygen uptake in the mutant strain is very low (see Fig. 2 and Table 2), indicating low activity of the putative lactate shunt. Furthermore, NADH reoxidation in the respiratory chain of glycolysing $Z$. mobilis has an obvious alternative the highly active alcohol dehydrogenase reaction. The increased D-lactate oxidase activity in the mutant strain under aerobic conditions, therefore, might have some other, so far unknown function.

Our results indicate that the $n d h$ gene product is the sole functional respiratory $\mathrm{NAD}(\mathrm{P}) \mathrm{H}$ dehydrogenase of $Z$. mobilis. On the other hand, the existing kinetic data (Kalnenieks et al., 1996) as well as genome information (Seo et al., 2005) seem to support the presence of more than one $\mathrm{NAD}(\mathrm{P}) \mathrm{H}$ dehydrogenase in its electron-transport chain. Kinetic analysis of $\mathrm{NADH}$ oxidation in membrane preparations revealed two components with different $K_{\mathrm{m}}$ values for NADH (Kalnenieks et al., 1996). The apparent $K_{\mathrm{m}}$ for the activity that prevails in anaerobically grown cells was found to be close to $7 \mu \mathrm{M}$, as for the energy-coupling NADH dehydrogenase complex I in E. coli, encoded by the nuo operon (Matsushita et al., 1987; Leif et al., 1995). The apparent $K_{\mathrm{m}}$ of the other component, prevailing in aerobically grown cells, was around $60 \mu \mathrm{M}$ (Kim et al., 1995; Kalnenieks et al., 1996), which is a typical value for the energy non-generating type II NADH dehydrogenase, encoded by $n d h$ (Yagi, 1991). At present the mechanistic basis for the observed 'nuo-like' (or the low- $K_{\mathrm{m}}$ ) component seems obscure, because: (i) the $Z$. mobilis genome does not contain any sequences homologous to $n u o$, and (ii) as demonstrated in the present work, inactivation of $n d h$ eliminates the entire respiratory $\mathrm{NAD}(\mathrm{P}) \mathrm{H}$ dehydrogenase activity in both aerobic and anaerobic culture.

Bacterial respiratory dehydrogenases are predominantly $\mathrm{NADH}$-specific (Yagi, 1991), yet the ability to oxidize $\mathrm{NADPH}$ in the respiratory chain has been reported for several bacteria. For C. glutamicum (Matsushita et al., 2001) and for Azotobacter vinelandii (Bertsova et al., 2001) it was demonstrated that NADPH oxidation in the respiratory chain is accomplished by the type II NADH dehydrogenase $(n d h)$, in full accordance with our present observations on $Z$. mobilis. Apart from $n d h$, the $Z$. mobilis genome (Seo et al., 2005) contains a gene homologous to $m d a B$ of E. coli, encoding an NADPH-specific quinone reductase. Homologues of the $\mathrm{MdaB}$ protein are known to act as antioxidant factors in many pathogenic bacteria, helping to cope with the oxidative stress accompanying inflammation processes (Wang \& Maier, 2004). The putative function of the MdaB homologue in Z. mobilis has not been investigated so far.

\section{Aerobic growth of the mutant strain}

Some of the aerobic batch cultivation experiments were carried out in a lab-scale fermenter with continuous monitoring of $\mathrm{pO}_{2}$. Remarkably, Ndh deficiency in $Z$. mobilis resulted in an increase of biomass yield, i.e. $Y_{\mathrm{X} / \mathrm{S}}$,

Table 2. Aerobic yields and specific rates of oxygen consumption of Z. mobilis strains Zm6 and $n d h:: \mathrm{cm}^{r}$

Yields (aerobic biomass yield, $Y_{\mathrm{X} / \mathrm{S}}$ : g dry weight per mole glucose consumed; and ethanol yield, $Y_{\mathrm{P} / \mathrm{S}}$ : g ethanol synthesized per g glucose consumed) were calculated for early stationary-phase cultures $\left(9 \mathrm{~h}\right.$ after inoculation) grown in the fermenter. The specific rates of oxygen consumption $\left(Q_{\mathrm{O}_{2}}\right.$, $\mu \mathrm{mol}$ oxygen per minute per g dry weight) refer to washed cell suspensions in $100 \mathrm{mM}$ phosphate buffer ( $\mathrm{pH}$ 6.9) with added glucose or ethanol $\left(10 \mathrm{~g} \mathrm{l}^{-1}\right)$. Data are means \pm SEM.

\begin{tabular}{|c|c|c|c|c|}
\hline Strain & $\begin{array}{c}Y_{\mathrm{X} / \mathrm{S}} \\
{\left[\text { g dry wt }\left(\mathrm{mol}_{\left.\text {glucose })^{-1}\right]}\right.\right.}\end{array}$ & $\begin{array}{c}Y_{\mathrm{P} / \mathrm{S}} \\
{\left[\text { g ethanol }(\mathrm{g} \text { glucose })^{-1}\right]}\end{array}$ & $\begin{array}{c}Q_{\mathrm{O}_{2}}(\text { glucose }) \\
{\left[\mathrm{U}(\mathrm{g} \text { dry } \mathrm{wt})^{-1}\right]}\end{array}$ & $\begin{array}{c}Q_{\mathrm{O}_{2}}(\text { ethanol }) \\
{\left[\mathrm{U}(\mathrm{g} \text { dry wt })^{-1}\right]}\end{array}$ \\
\hline $\mathrm{Zm} 6$ & $4.1( \pm 1.5)$ & $0.22( \pm 0.04)$ & $0.103( \pm 0.020)$ & $0.215( \pm 0.002)$ \\
\hline$n d h:: \mathrm{cm}^{r}$ & $8.6( \pm 1.6)$ & $0.39( \pm 0.09)$ & $0.013( \pm 0.005)$ & 0.000 \\
\hline
\end{tabular}


cell yield normalized with respect to glucose consumption (Table 2), and stimulation of aerobic growth. The mutant strain also grew substantially faster than Zm6, at the end of the exponential phase typically reaching a threefold higher biomass concentration (Fig. 2). However, the downshift of $\mathrm{pO}_{2}$ that occurred during the growth of $\mathrm{Zm} 6$ was much larger than that seen in the mutant, indicating a higher respiration rate of the parent culture. Accordingly, the mutant culture showed an increased aerobic ethanol yield $\left(Y_{\mathrm{P} / \mathrm{S}}\right.$, Table 2), because more reducing equivalents were diverted towards ethanol synthesis. As expected, the oxygen uptake rate of a washed $n d h:: \mathrm{cm}^{r}$ cell suspension was close to zero (Table 2). No oxygen consumption could be detected with ethanol, implying that in $Z$. mobilis, ethanol oxidation proceeds solely via $\mathrm{NAD}^{+}$-dependent alcohol dehydrogenases. The remaining respiratory activity of cell suspensions with glucose most probably is related to some type of lactate shunt, as discussed above.

In general, the aerobic growth of the ndh-deficient mutant strain resembles that of $\mathrm{Zm} 6$ in the presence of cyanide (Kalnenieks et al., 2000, 2003). However, the results obtained with the $n d h$-deficient mutant are less ambiguous, and help to draw a more precise picture of the aerobic growth stimulation of $Z$. mobilis. Cyanide typically caused the growth stimulation of $\mathrm{Zm} 6$ after a prolonged lag phase, when, following an initial period of complete inhibition, the re-emerging respiration reached $30-50 \%$ of the respiration rate in the control culture (Kalnenieks et al., 2000). Hence, an important question was left: (i) does the stimulating effect result simply from inhibition of the bulk oxygen consumption, or (ii) is some specific, energetically efficient and cyanide-resistant branch of the respiratory chain contributing to the aerobic growth? Our present results with the $n d h:: \mathrm{cm}^{r}$ strain tend to support the first alternative, because the oxygen uptake in the mutant strain would be too low for any measurable impact of oxidative phosphorylation. We therefore suggest that the observed elevation of the aerobic growth rate and biomass yield $\left(Y_{\mathrm{X} / \mathrm{S}}\right)$ of $Z$. mobilis does not result from extra ATP generation by oxidative phosphorylation, but occurs whenever the NADH flux is redirected from respiration to ethanol synthesis, so that less acetaldehyde, the toxic precursor of ethanol (Wecker \& Zall, 1987), is accumulated in the culture.

The key role of acetaldehyde was reinforced by the present finding that vigorous aeration (hyperventilation) of the shaken flask cultures of Zm6 improved the aerobic growth rate. As described above, the batch cultivations in shaken flasks were carried out under strictly anaerobic conditions (gassing of cultures with oxygen-free nitrogen gas), aerobically on the shaker, and aerobically on the shaker with hyperventilation. Under strictly anaerobic conditions, the growth curves of $\mathrm{Zm} 6$ and $n d h:: \mathrm{cm}^{r}$ were identical (not shown). However, the aerobic behaviour of the two strains differed substantially (Fig. 3). In shaken flasks without hyperventilation Zm6 accumulated acetaldehyde and grew much more slowly than the mutant. At the early stationary phase, acetaldehyde concentration reached

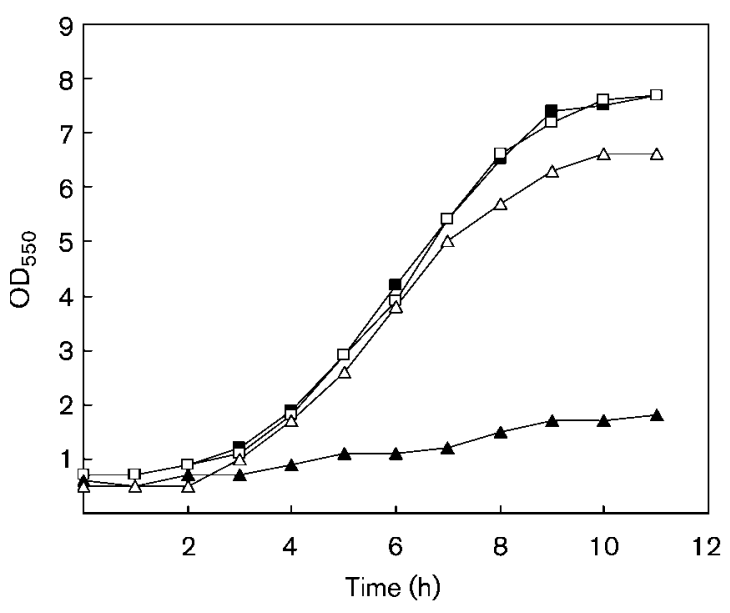

Fig. 3. Aerobic batch cultivation of $\operatorname{Zm} 6(\boldsymbol{\Lambda}, \boldsymbol{\square})$ and $n d h:: \mathrm{cm}^{r}(\triangle$, $\square)$ in shaken flasks at 120 r.p.m. $(\boldsymbol{\Lambda}, \triangle)$ and in shaken flasks with additional aeration at $11 \mathrm{~min}^{-1}(\boldsymbol{\square}, \square)$.

$33 \mathrm{mM}\left(1.4 \mathrm{~g} \mathrm{l}^{-1}\right)$. In the mutant strain, due to its low respiration rate, accumulation of acetaldehyde was negligible; its concentration at the end of the batch cultivation did not exceed $0.6 \mathrm{mM}$. Hyperventilation of the shaken flask cultures barely affected the growth of $n d h:: \mathrm{cm}^{r}$, yet greatly improved that of $\mathrm{Zm} 6$. Acetaldehyde concentration in both hyperventilated cultures was low: $0.5 \mathrm{mM}$ for $\mathrm{Zm} 6$ and $0.4 \mathrm{mM}$ for $n d h:: \mathrm{cm}^{r}$. We may conclude that either a low rate of acetaldehyde generation (as in $n d h:: \mathrm{cm}^{r}$ ) or an efficient removal of acetaldehyde (as in the hyperventilated Zm6) is of prime importance for aerobic growth stimulation in $Z$. mobilis to take place.

Notably, however, the aerobic growth stimulation of Zm6 never extended beyond the limits imposed by its fermentative catabolism. The hyperventilation of the shaken flask cultures clearly demonstrated that, even at very low acetaldehyde concentrations, the respiratory chain did not contribute to the aerobic batch growth of $Z$. mobilis: hyperventilated Zm6 and $n d h:: \mathrm{cm}^{r}$ showed identical growth curves (Fig. 3). Thus, acetaldehyde acting as a potent inhibitor of growth is not the key factor that causes the deficiency of oxidative phosphorylation in growing $Z$. mobilis.

\section{ACKNOWLEDGEMENTS}

This work was funded by grant 04.1101 of the Latvian Council of Science and by Royal Society fellowship 2005/R3 (to U.K.). The authors are grateful to Dr Malda M. Toma for valuable help in cultivation experiments.

\section{REFERENCES}

Belaïch, J. P. \& Senez, J. C. (1965). Influence of aeration and pantothenate on growth yields of Zymomonas mobilis. J Bacteriol 89, $1195-1200$. 
Bertsova, Y. V., Bogachev, A. V. \& Skulachev, V. P. (2001). Noncoupled NADH:ubiquinone oxidoreductase of Azotobacter vinelandii is required for diazotrophic growth at high oxygen concentrations. J Bacteriol 183, 6869-6874.

Bringer, S., Finn, R. K. \& Sahm, H. (1984). Effect of oxygen on the metabolism of Zymomonas mobilis. Arch Microbiol 139, 376-381.

Calhoun, M. W., Oden, K. L., Gennis, R. B., de Mattos, J. T. \& Neijssel, J. (1993). Energetic efficiency of Escherichia coli: effects of mutations in components of the aerobic respiratory chain. J Bacteriol 175, 3020-3025.

Conway, T. (1992). The Entner-Doudoroff pathway: history, physiology and molecular biology. FEMS Microbiol Rev 9, 1-27.

Demirtas, M. U., Kolhatkar, A. \& Kilbane, J. J., 2nd (2003). Effect of aeration and agitation on growth rate of Thermus thermophilus in batch mode. J Biosci Bioeng 95, 113-117.

Dien, B. S., Cotta, M. A. \& Jeffries, T. W. (2003). Bacteria engineered for fuel ethanol production: current status. Appl Microbiol Biotechnol 63, 258-266.

Kalnenieks, U. (2006). Physiology of Zymomonas mobilis: some unanswered questions. Adv Microb Physiol 51, 73-117.

Kalnenieks, U., de Graaf, A. A., Bringer-Meyer, S. \& Sahm, H. (1993). Oxidative phosphorylation in Zymomonas mobilis. Arch Microbiol 160, 74-79.

Kalnenieks, U., Galinina, N., Irbe, I. \& Toma, M. M. (1995). Energy coupling sites in the electron transport chain of Zymomonas mobilis. FEMS Microbiol Lett 133, 99-104.

Kalnenieks, U., Galinina, N., Toma, M. M. \& Skards, I. (1996). Electron transport chain in aerobically cultivated Zymomonas mobilis. FEMS Microbiol Lett 143, 185-189.

Kalnenieks, U., Galinina, N., Bringer-Meyer, S. \& Poole, R. K. (1998). Membrane D-lactate oxidase in Zymomonas mobilis: evidence for a branched respiratory chain. FEMS Microbiol Lett 168, 91-97.

Kalnenieks, U., Galinina, N., Toma, M. M. \& Poole, R. K. (2000). Cyanide inhibits respiration yet stimulates aerobic growth of Zymomonas mobilis. Microbiology 146, 1259-1266.

Kalnenieks, U., Toma, M. M., Galinina, N. \& Poole, R. K. (2003). The paradoxical cyanide-stimulated respiration of Zymomonas mobilis: cyanide sensitivity of alcohol dehydrogenase (ADH II). Microbiology 149, 1739-1744.

Kalnenieks, U., Galinina, N., Toma, M. M., Pickford, J. L., Rutkis, R. \& Poole, R. K. (2006). Respiratory behaviour of a Zymomonas mobilis adhB: $\mathrm{kan}^{r}$ mutant supports the hypothesis of two alcohol dehydrogenase isoenzymes catalysing opposite reactions. FEBS Lett 580, 5084-5088.

Kim, Y. J., Song, K.-B. \& Rhee, S.-K. (1995). A novel aerobic respiratory chain-linked $\mathrm{NADH}$ oxidase system in Zymomonas mobilis. J Bacteriol 177, 5176-5178.

Leif, H., Sled, V. D., Ohnishi, T., Weiss, H. \& Friedrich, T. (1995). Isolation and characterization of the proton-translocating NADH:ubiquinone oxidoreductase from Escherichia coli. Eur J Biochem 230, 538-548.

Liang, C.-C. \& Lee, W.-C. (1998). Characteristics and transformation of Zymomonas mobilis with plasmid pKT230 by electroporation. Bioprocess Eng 19, 81-85.

Markwell, M. A. K., Haas, S. M., Bieber, L. L. \& Talbert, N. E. (1978). A modification of the Lowry procedure to simplify protein determination in membrane and lipoprotein samples. Anal Biochem 87, 206-210.
Matsushita, K., Ohnishi, T. \& Kaback, R. H. (1987). NADHubiquinone oxidoreductases of the Escherichia coli aerobic respiratory chain. Biochemistry 26, 7732-7737.

Matsushita, K., Otofuji, A., Iwahashi, M., Toyama, H. \& Adachi, O. (2001). NADH dehydrogenase of Corynebacterium glutamicum. Purification of an NADH dehydrogenase II homolog able to oxidize NADPH. FEMS Microbiol Lett 204, 271-276.

Nantapong, N., Kugimiya, Y., Toyama, H., Adachi, O. \& Matsushita, K. (2004). Effect of NADH dehydrogenase-disruption and over-expression on respiration-related metabolism in Corynebacterium glutamicum KY 9714. Appl Microbiol Biotechnol 66, 187-193.

Pankova, L. M., Shvinka, Y. E., Beker, M. E. \& Slava, E. E. (1985). Effect of aeration on Zymomonas mobilis metabolism. Mikrobiologiia 54, 141-145.

Poole, R. K. \& Cook, G. M. (2000). Redundancy of aerobic respiratory chains in bacteria? Routes, reasons and regulation. Adv Microb Physiol 43, 165-224.

Reyes, L. \& Scopes, R. K. (1991). Membrane-associated ATPase from Zymomonas mobilis; purification and characterization. BBA 1068, 174-178.

Rogers, P. L. K., Lee, J., Skotnicki, M. L. \& Tribe, D. E. (1982). Ethanol production by Zymomonas mobilis. Adv Biochem Eng 23, 37-84.

Sambrook, J., Fritsch, E. F. \& Maniatis, T. (1989). Molecular Cloning: a Laboratory Manual, 2nd edn. Cold Spring Harbor, NY: Cold Spring Harbor Laboratory.

Schmehl, M., Jahn, A., Meyer zu Vilsendorf, A., Hennecke, S., Masepohl, B., Schuppler, M., Marxer, M., Oelze, J. \& Klipp, W. (1993). Identification of a new class of nitrogen fixation genes in Rhodobacter capsulatus: a putative membrane complex involved in electron transport to nitrogenase. Mol Gen Genet 241, 602-615.

Seo, J.-S., Chong, H., Park, H. S., Yoon, K.-O., Jung, C., Kim, J. J., Hong, J. H., Kim, H., Kim, J. H. \& other authors (2005). The genome sequence of the ethanologenic bacterium Zymomonas mobilis ZM4. Nat Biotechnol 23, 63-68.

Sprenger, G. A. (1996). Carbohydrate metabolism in Zymomonas mobilis: a catabolic highway with some scenic routes. FEMS Microbiol Lett 145, 301-307.

Strohdeicher, M., Neuß, B., Bringer-Meyer, S. \& Sahm, H. (1990). Electron transport chain of Zymomonas mobilis. Interaction with the membrane-bound glucose dehydrogenase and identification of ubiquinone 10. Arch Microbiol 154, 536-543.

Viikari, L. (1986). By-product formation in ethanol fermentation by Zymomonas mobilis. Technical Research Centre of Finland. Publication 27.

Viikari, L. \& Berry, D. R. (1988). Carbohydrate metabolism in Zymomonas. Crit Rev Biotechnol 7, 237-261.

Wang, G. \& Maier, R. J. (2004). An NADPH quinone reductase of Helicobacter pylori plays an important role in oxidative stress resistence and host colonization. Infect Immun 72, 1391-1396.

Wecker, M. S. A. \& Zall, R. R. (1987). Production of acetaldehyde by Zymomonas mobilis. Appl Environ Microbiol 53, 2815-2820.

Yagi, T. (1991). Bacterial NADH-quinone oxidoreductases. J Bioenerg Biomembr 23, 211-225.

Edited by: R. van Spanning 